ARTICLE

\title{
Phase controlled synthesis of transition metal carbide nanocrystals by ultrafast flash Joule heating
}

\author{
Bing Deng (1) 1, Zhe Wang (1) 1, Weiyin Chen (1) 1, John Tianci Li,2, Duy Xuan Luong ${ }^{1}$, Robert A. Carter (1) ${ }^{1}$, \\ Guanhui Gao², Boris I. Yakobson (1) ${ }^{1,2,3}$, Yufeng Zhao (1) ${ }^{2,4 凶}$ \& James M. Tour (1D) 1,2,3,5凶
}

Nanoscale carbides enhance ultra-strong ceramics and show activity as high-performance catalysts. Traditional lengthy carburization methods for carbide syntheses usually result in coked surface, large particle size, and uncontrolled phase. Here, a flash Joule heating process is developed for ultrafast synthesis of carbide nanocrystals within $1 \mathrm{~s}$. Various interstitial transition metal carbides ( $\mathrm{TiC}, \mathrm{ZrC}, \mathrm{HfC}, \mathrm{VC}, \mathrm{NbC}, \mathrm{TaC}, \mathrm{Cr}_{2} \mathrm{C}_{3}, \mathrm{MoC}$, and $\mathrm{W}_{2} \mathrm{C}$ ) and covalent carbides $\left(\mathrm{B}_{4} \mathrm{C}\right.$ and $\left.\mathrm{SiC}\right)$ are produced using low-cost precursors. By controlling pulse voltages, phase-pure molybdenum carbides including $\beta-\mathrm{Mo}_{2} \mathrm{C}$ and metastable $\alpha-\mathrm{MoC}_{1-x}$ and $\eta-\mathrm{MoC}_{1-x}$ are selectively synthesized, demonstrating the excellent phase engineering ability of the flash Joule heating by broadly tunable energy input that can exceed $3000 \mathrm{~K}$ coupled with kinetically controlled ultrafast cooling $\left(>10^{4} \mathrm{~K} \mathrm{~s}^{-1}\right)$. Theoretical calculation reveals carbon vacancies as the driving factor for topotactic transition of carbide phases. The phase-dependent hydrogen evolution capability of molybdenum carbides is investigated with $\beta-\mathrm{Mo}_{2} \mathrm{C}$ showing the best performance.

\footnotetext{
${ }^{1}$ Department of Chemistry, Rice University, Houston, TX 77005, USA. ${ }^{2}$ Department of Materials Science and NanoEngineering, Rice University, Houston, TX 77005, USA. ${ }^{3}$ Smalley-Curl Institute, Rice University, Houston, TX 77005, USA. ${ }^{4}$ Corban University, Salem, Oregon 97317, USA. ${ }^{5}$ NanoCarbon Center and

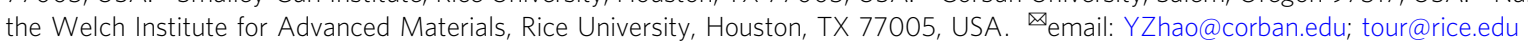


C arbides are an important class of materials with broad applications in electronics, ceramics, and energy conversion, due to their extreme hardness, high thermal stability, and widely tunable electronic structures. Nanosized transition metal carbides (TMCs) have been widely used as the precursors for ultra-hard and ultra-strong ceramics ${ }^{1-3}$, highperformance electrochemical catalysts because of their platinum-like electronic structures ${ }^{4-8}$, and catalyst supports due to the strong metal-substrate interactions ${ }^{9-11}$. Traditional methods for bulk carbide syntheses include carburization of metal precursors with gaseous carbon precursors or sintering of metal precursors with graphitic carbon at high temperature ${ }^{12}$. These procedures can be problematic since they result in coked carbide surfaces due to the excessive supply of carbon sources, and large particle sizes with low surface areas that are detrimental to catalytic performance ${ }^{13,14}$.

Much effort has been devoted to synthesizing carbides with fine particle sizes, including temperature-programmed reduction (TPR) $)^{15}$, carbothermic reduction of metal precursors ${ }^{16,17}$, laser spray pyrolysis of metal complexes ${ }^{18}$, and solution-based precipitation and carburization ${ }^{19}$. The TPR method is versatile for high-surface-area metal carbide synthesis but requires welloptimized reaction windows ${ }^{20}$. The carbothermic reduction of metal precursors in a furnace is universal in the synthesis of $\mathrm{TMCs}^{16}$; however, extended high-temperature conditions are essential to compensate the slow solid-solid reaction kinetics, which inevitably result in sintering or agglomeration ${ }^{17}$. To avoid severe agglomeration, a microwave combustion method is developed for rapid synthesis of $\mathrm{Mo}_{2} \mathrm{C}$ and $\mathrm{WC}$ nanodots within $2 \mathrm{~min}^{21}$. The pyrolysis of metal complexes involves the use of costly and toxic metal-organic compounds such as $\mathrm{Cp}_{2} \mathrm{Mo}_{2}(\mathrm{CO})_{6}$ for the synthesis of $\mathrm{Mo}_{2} \mathrm{C}^{18,22}$, and $\mathrm{W}(\mathrm{CO})_{6}$ for the synthesis of $\mathrm{WC}^{23}$. The type of carbide is also limited by the availability of volatile metal compounds. The solution-based precipitation and carburization requires long annealing times for full conversion. For example, annealing at $850^{\circ} \mathrm{C}$ for 12 to $24 \mathrm{~h}$ is needed for the synthesis of MoC using ammonium heptamolybdate $\left(\left(\mathrm{NH}_{4}\right)_{6} \mathrm{Mo}_{7} \mathrm{O}_{24} \cdot 4 \mathrm{H}_{2} \mathrm{O}\right)$ as the precursor ${ }^{19}$.

Recently, several non-conventional electrical thermal processes have been developed towards energy-efficient high-temperature synthesis ${ }^{24-26}$. The carbothermal shock (CTS) process uses short current pulses for the synthesis of high-entropy alloy nanoparticles on carbon supports at $\sim 2000 \mathrm{~K}^{26}$. The ultrahigh temperature sintering (UHS) based on current-induced heating is proposed for sintering and screening of ceramics within $10 \mathrm{~s}^{24}$. The spark plasma sintering (SPS) applies an electric current for the reactive carbothermic synthesis of zirconium carbide $(\mathrm{ZrC})$ in $10 \mathrm{~min}^{25}$. However, these approaches are targeting the sintering of bulk ceramics and lack the ability in the synthesis of fine nanocrystals. Most importantly, phases and crystal surface structure play significant roles in the behavior of carbides, such as in their hydrogen adsorption/desorption energy 7,27 . However, there are very few procedures to selectively engineer the phases and crystal surfaces of carbides for maximal performance ${ }^{7,19}$.

To meet those demands, here, we develop the ultrafast flash Joule heating $(\mathrm{FJH})$ method for the general synthesis of coke-free and phase-controlled carbide nanocrystals within $1 \mathrm{~s}$. A milliseconds current pulse is passed through the precursors, which brings the sample to an ultrahigh temperature $(>3000 \mathrm{~K})$ and then it is rapidly cooled to room temperature $\left(>10^{4} \mathrm{~K} \mathrm{~s}^{-1}\right)$. Thirteen important element carbides are synthesized, including interstitial TMCs of TiC, $\mathrm{ZrC}, \mathrm{HfC}, \mathrm{VC}, \mathrm{NbC}, \mathrm{TaC}, \mathrm{Cr}_{2} \mathrm{C}_{3}, \mathrm{MoC}$, and $\mathrm{W}_{2} \mathrm{C}$, and covalent carbides of $\mathrm{B}_{4} \mathrm{C}$ and $\mathrm{SiC}$, demonstrating the excellent generality. Moreover, by controlling the $\mathrm{FJH}$ pulse voltages, phase-pure molybdenum carbides including thermodynamically stable $\beta-\mathrm{Mo}_{2} \mathrm{C}$, and metastable $\alpha-\mathrm{MoC}_{1-\mathrm{x}}$ and
$\eta-\mathrm{MoC}_{1-\mathrm{x}}$ are selectively synthesized, showing the phase engineering ability of the synergistic electrical-thermal process. The phase-dependent hydrogen evolution reaction (HER) performance of molybdenum carbides is discovered. The $\beta-\mathrm{Mo}_{2} \mathrm{C}$ exhibits the best HER performance with an overpotential of $-220 \mathrm{mV}$, Tafel slope of $68 \mathrm{mV} \mathrm{dec}{ }^{-1}$, and good durability. This rapid carbide synthesis method could realize low-cost, mass production of nanocrystalline carbides at only 2.2 to $8.6 \mathrm{~kJ} \mathrm{~g}^{-1}$ in electrical energy.

\section{Results}

Ultrafast synthesis of carbide nanocrystals by flash Joule heating. In a typical process, a mixture of metal precursors and commercial carbon black was slightly compressed inside a quartz tube between two graphite electrodes (Fig. 1a). The widely applicable metal precursors could be elemental metal $(\mathrm{M})$, metal oxides $\left(\mathrm{MO}_{\mathrm{x}}\right)$, chlorides $\left(\mathrm{MCl}_{\mathrm{x}}\right)$, and hydroxides $\left(\mathrm{M}(\mathrm{OH})_{\mathrm{x}}\right)$, etc. The carbon black simultaneously works as the carbon source for carbothermic reduction and the conductive additive. The two electrodes were connected to a capacitor bank, which was first charged by a power supply and then brought the precursors to a high temperature by high voltage discharging (Supplementary Fig. 1). In a typical FJH process with a voltage of $100 \mathrm{~V}$ and a sample resistance of $1 \Omega$, the current passing through the sample was recorded to be $\sim 100 \mathrm{~A}$ in $\sim 50 \mathrm{~ms}$ discharge time (Fig. 1b).

A rapid light emission was observed during the $\mathrm{FJH}$ process (Fig. 1c, inset). The temperature was measured by fitting the blackbody radiation spectra of the sample (Fig. 1c, Supplementary Fig. 2). The highest temperatures obtained at $80 \mathrm{~V}$ and $100 \mathrm{~V} \mathrm{FJH}$ were estimated to be $\sim 2700 \mathrm{~K}$ and $\sim 3000 \mathrm{~K}$, respectively (Fig. 1d). The cooling rate is ultrafast and on the order of $10^{4} \mathrm{~K} \mathrm{~s}^{-1}$. The temperature distribution of the sample is simulated by using the finite element method (FEM) (Supplementary Note 1), which further provides insight into the effects of $\mathrm{FJH}$ parameters on the reachable temperature. It is found that higher temperature values could be obtained by applying a larger FJH voltage and suitable sample electrical conductivity (Supplementary Fig. 3). In contrast, a higher thermal conductivity of the sample results in a lower temperature due to a faster thermal dissipation. The temperature map shows that the temperature distribution is uniform throughout the entire sample (Supplementary Fig. 4), demonstrating the homogeneous heating feature of the FJH process.

$\mathrm{FJH}$ of the sample to such a high temperature $(\sim 3000 \mathrm{~K})$ volatilizes most of the non-carbon components. According to the temperature-vapor pressure relationships (Fig. 1e), all of the representative metal precursors, including elemental metals and metal oxides and chlorides, have higher vapor pressure than carbon, which sublimes at $\sim 3900 \mathrm{~K}^{28}$. As a result, the metal precursors are the volatile components, and the carbon source remains solid during the reaction. In this case, metal precursor vapors react with the carbon to form the metal carbides, which we define as the inverse gas-solid reaction interface (Fig. 1a, route i). In contrast, in the traditional carburization process ${ }^{12}$, a gaseous hydrocarbon such as methane $\left(\mathrm{CH}_{4}\right)$ is introduced to the solid metal precursors. The carbon diffusion through the solid-gas interface is usually fast and results in a coked carbide surface due to the excessive supply of carbon sources (Fig. 1a, route ii), which can passivate the catalytic activity of the final products ${ }^{7}$.

Phase controlled synthesis of molybdenum carbide nanocrystals. We first tried to synthesize molybdenum carbides that are attractive for catalysts ${ }^{11,19,29,30}$. The phases of molybdenum carbide are complex due to their temperature-, composition-, and vacancy-dependent stability ${ }^{31}$. Different phases have 


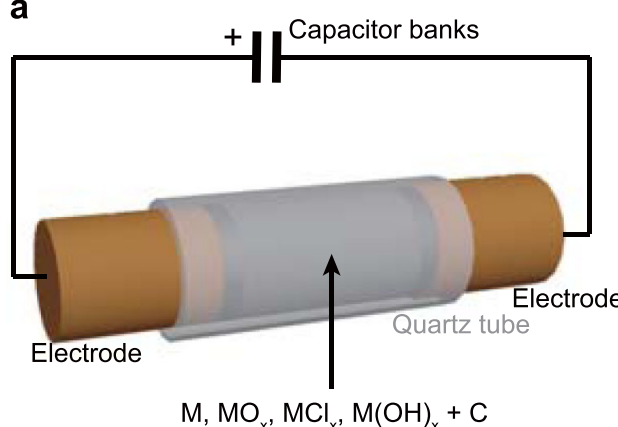

b
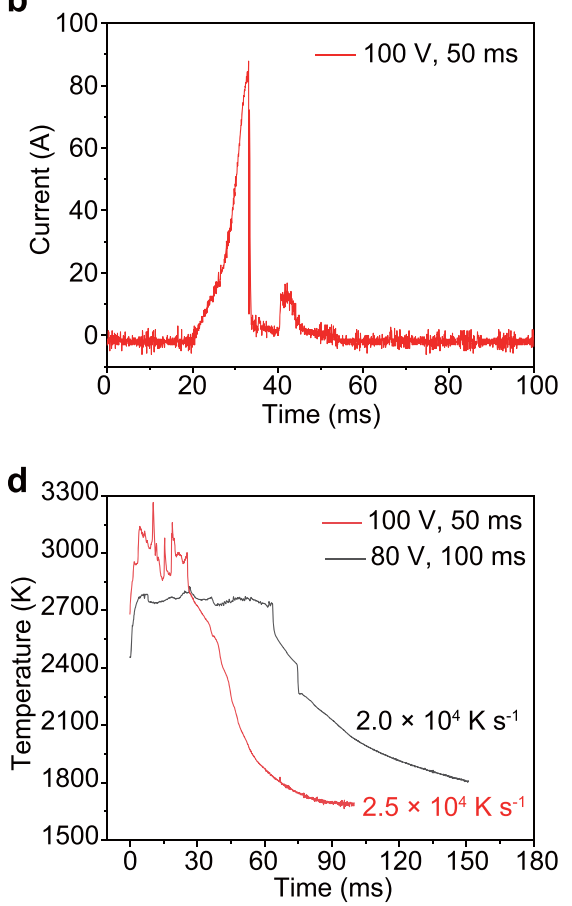

i) Inverse gas-solid reaction interface

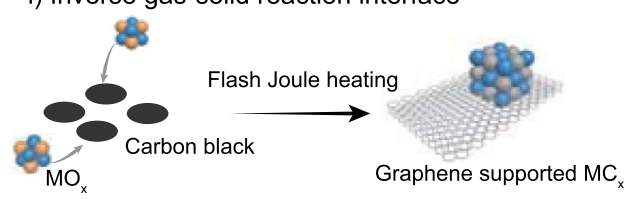

ii) Solid-gas reaction interface

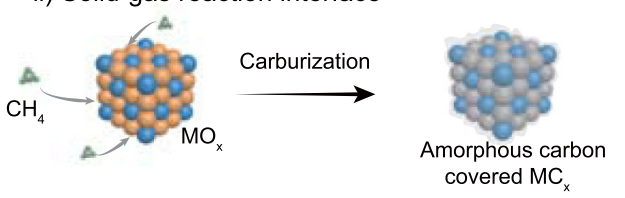

C

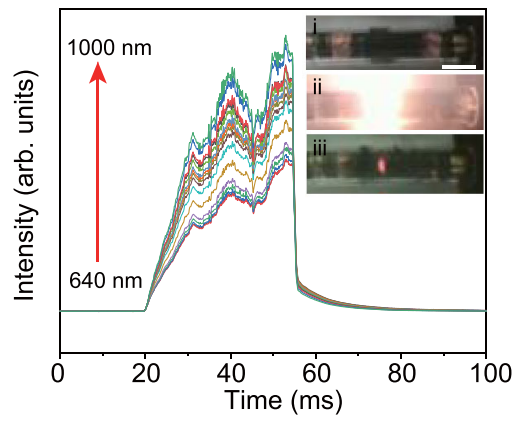

e

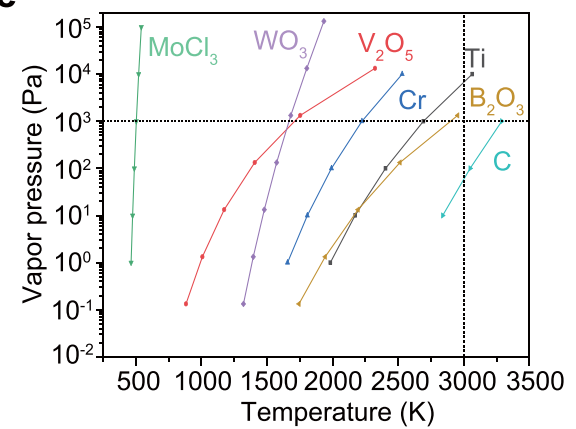

Fig. 1 Ultrafast synthesis of carbides by flash Joule heating (FJH). a Schematic of FJH synthesis of carbides. Route (i) demonstrates the high-temperature $\mathrm{FJH}$ process disclosed here. Route (ii) demonstrates the traditional carburization process. b Current measurement during the FJH process. c Real-time spectral radiance at wavelength of 640-1000 nm. Inset, the pictures of the sample before FJH (i), during FJH (ii), and in rapid cooling (iii). Scale bar, $1 \mathrm{~cm}$. d Real-time temperature measurement by fitting the blackbody radiation from the sample during the FJH process. e Temperature-vapor pressure relationships for various metal precursors and carbon. The vertical dashed line denotes temperature at $3000 \mathrm{~K}$, and the horizontal dashed line denotes vapor pressure at $10^{3} \mathrm{~Pa}$.

distinct geometric and electronic structures ${ }^{27,32}$, and the catalytically relevant phases are hexagonal $\beta-\mathrm{Mo}_{2} \mathrm{C}^{19,30,33}$, cubic $\alpha-\mathrm{MoC}_{1-\mathrm{x}} 11,32,34$, and hexagonal $\eta-\mathrm{MoC}_{1-\mathrm{x}}{ }^{34}$ (Supplementary Fig. 5). $\mathrm{MoCl}_{3}$ was chosen as the precursor because of its high vapor pressure (Fig. 1e). We found that three pure phases of molybdenum carbides could be selectively synthesized by adjusting $\mathrm{FJH}$ voltages (Fig. $2 \mathrm{a}, \mathrm{b}$ ). $\beta-\mathrm{Mo}_{2} \mathrm{C}$ phase was produced under the voltage of $30 \mathrm{~V}$ according to $\mathrm{X}$-ray diffraction (XRD) (Fig. 2a, bottom); when the voltage was increased to $60 \mathrm{~V}$, pure $\alpha-\mathrm{MoC}_{1-\mathrm{x}}$ phase was obtained (Fig. 2a, middle); further increasing the voltage to $120 \mathrm{~V}$ led to $\eta-\mathrm{MoC}_{1-\mathrm{x}}$ (Fig. 2a, top). Note that the diffraction peak at $\sim 26^{\circ}$ is attributed to the graphene support (Supplementary Fig. 6). The phase transformation from hexagonal $\beta-\mathrm{Mo}_{2} \mathrm{C}$ to cubic $\alpha-$ $\mathrm{MoC}_{1-\mathrm{x}}$ and then to hexagonal $\eta-\mathrm{MoC}_{1-\mathrm{x}}$ is a newly found topotactic transition pathway, which is distinct from the previous report ${ }^{19}$, where the $\alpha-\mathrm{MoC}_{1-\mathrm{x}}$ is transformed to $\beta-\mathrm{Mo}_{2} \mathrm{C}$ after a $\sim 24 \mathrm{~h}$ annealing at $850^{\circ} \mathrm{C}$, and $\eta-\mathrm{MoC}_{1-\mathrm{x}}$ is only stabilized by using a $\mathrm{NiI}_{2}$ additive at a higher temperature.
To investigate the electronic structures, X-ray photoelectron spectroscopy (XPS) spectra of the Mo $3 d$ core level was collected (Fig. 2c). Mo $3 d$ spectra are split into $3 d_{3 / 2}$ and $3 d_{5 / 2}$ peaks. The peak fitting shows four chemical states of Mo in molybdenum carbides, including $\mathrm{Mo}^{0}, \mathrm{Mo}^{2+}, \mathrm{Mo}^{4+}$, and $\mathrm{Mo}^{6+}$. The dominant $\mathrm{Mo}^{0}$ peak and the smaller peak of $\mathrm{Mo}^{2+}$ are attributed to the molybdenum carbide due to the coexistence of Mo-Mo and Mo-C bonds in molybdenum carbides ${ }^{19} . \mathrm{Mo}^{4+}$ and $\mathrm{Mo}^{6+}$ are assigned to $\mathrm{MoO}_{2}$ and $\mathrm{MoO}_{3}$, respectively, due to the surface oxidation of molybdenum carbides when exposed to air ${ }^{19,30}$. The quantitative analysis of the ratios of Mo chemical states shows the high oxidation states $\left(\mathrm{Mo}^{4+}\right.$ and $\left.\mathrm{Mo}^{6+}\right)$ in $\eta-\mathrm{MoC}_{1-\mathrm{x}}$ are larger than those in $\beta-\mathrm{Mo}_{2} \mathrm{C}$ and $\alpha-\mathrm{MoC}_{1-\mathrm{x}}$ (Supplementary Fig. 7), indicating that $\beta-\mathrm{Mo}_{2} \mathrm{C}$ is the most oxidation resistant phase followed by $\alpha-\mathrm{MoC}_{1-\mathrm{x}}$.

The morphology characterization by scanning electron microscopy (SEM) shows the fine powder feature of all three carbide phases (Supplementary Fig. 8). The energy dispersive spectroscopy (EDS) mapping images show a uniform distribution of 

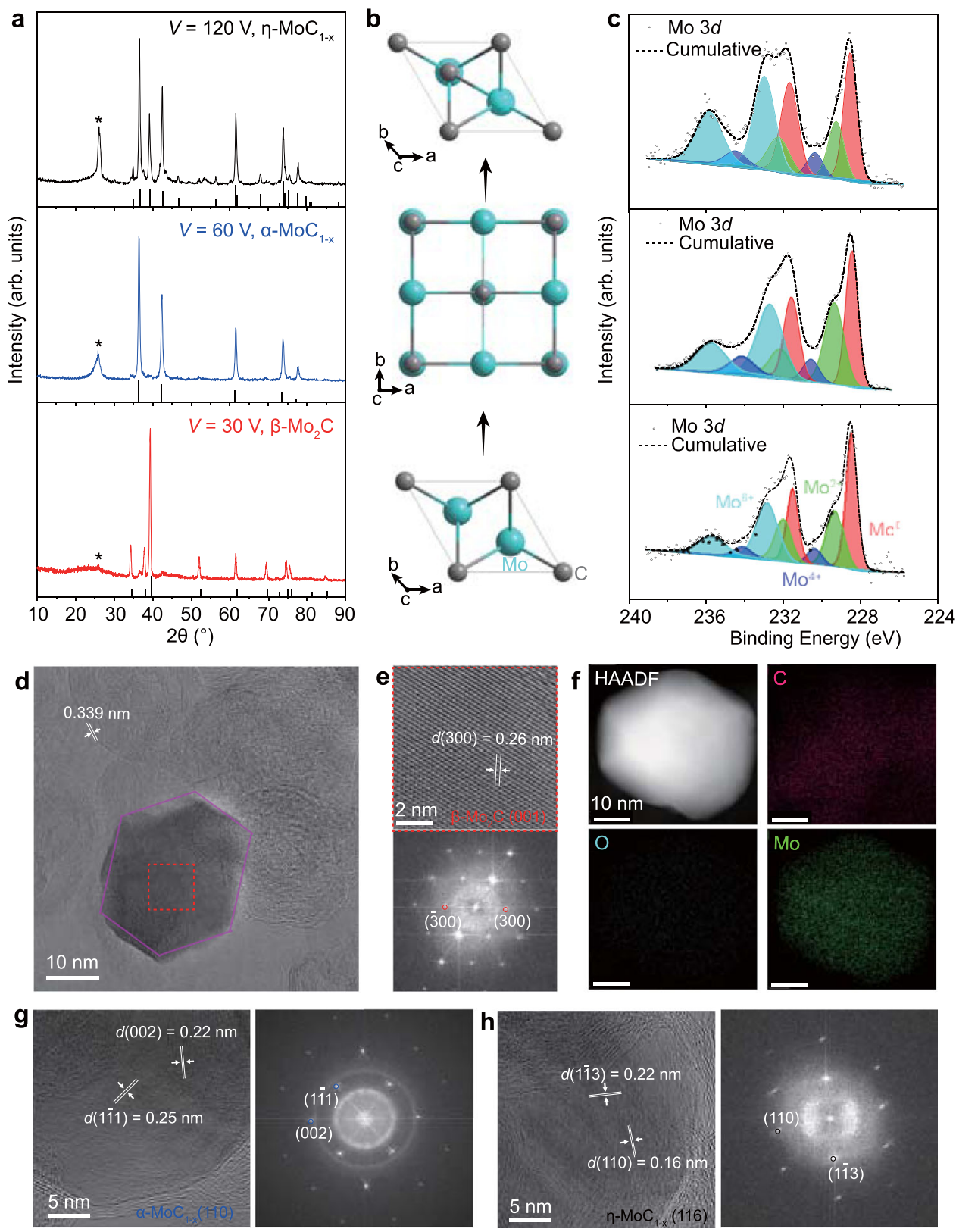

Fig. 2 Phase controlled synthesis of molybdenum carbide. a X-ray diffraction (XRD) patterns of $\beta-M_{2} C_{1} \alpha-M o C_{1-x}$, and $\eta-M o C_{1-x}$ synthesized at voltage $(\mathrm{V})$ of $30 \mathrm{~V}, 60 \mathrm{~V}$, and $120 \mathrm{~V}$, respectively. The PDF reference cards for each are $\beta-\mathrm{Mo}_{2} \mathrm{C}, 35-0787 ; \alpha-\mathrm{MoC}_{1-x}, 65-8092 ;$ and $\eta-\mathrm{MoC}_{1-x}, 08-0384$. The peak at $26^{\circ}$ (star) is attributed to graphene support. $\mathbf{b}$, Crystal structures of three phases of molybdenum carbides. $\beta-\mathrm{Mo}_{2} \mathrm{C}$ is hexagonal with $\mathrm{ABAB}$ stacking (bottom), $\alpha-M_{o C} C_{1-x}$ is cubic (middle), and $\eta-M_{o c} C_{1-x}$ is hexagonal with $A B C A B C$ stacking (top). $\mathbf{c} X$-ray photoemission spectroscopy (XPS) spectra of three phases of molybdenum carbides. d Bright-field transmission electron microscopy (BF-TEM) image of a $\beta-\mathrm{Mo}_{2} \mathrm{C}$ nanocrystal supported on graphene. The $0.339 \mathrm{~nm}$ corresponds to interplanar distance $(d)$ of graphene. The purple hexagon depicts the shape of the nanocrystal. e High-resolution transmission electron microscopy (HRTEM) image of $\beta-\mathrm{Mo}_{2} \mathrm{C}$ (top) and corresponding fast Fourier transform (FFT) pattern (bottom). $\mathbf{f}$ High-angle annular dark-field scanning transmission electron microscopy (HAADF-STEM) image and energy dispersive spectroscopy (EDS) element maps of $\beta$-Mo ${ }_{2} \mathrm{C}$. $\mathbf{g}$ HRTEM image of $\alpha-M_{o C} C_{1-x}$ (left) and corresponding FFT pattern (right). $\mathbf{h}$, HRTEM image of $\eta-M_{o} C_{1-x}$ (left) and corresponding FFT pattern (right).

Mo and C (Supplementary Figs. 8, 9). Transmission electron microscopy (TEM) and XRD were used to characterize the size and crystallinity of the molybdenum carbides. The particle sizes of the molybdenum carbide phases are determined by the $\mathrm{FJH}$ voltages (Supplementary Fig. 10). The $\beta-\mathrm{Mo}_{2} \mathrm{C}$ synthesized at the lowest voltage has the largest average size of $\sim 26.4 \mathrm{~nm}$, followed by $\alpha-M_{0} C_{1-\mathrm{x}}(\sim 21.2 \mathrm{~nm})$ and $\eta-\mathrm{MoC}_{1-\mathrm{x}}(\sim 20.1 \mathrm{~nm})$. The smaller particle size obtained under higher voltage could be attributed to the faster nucleation kinetics at higher temperature ${ }^{35}$. The particle size values measured by TEM match well with the crystal size values determined by XRD using the Halder-Wagner method (Supplementary Table 2), indicating the single-crystal feature of the synthesized carbide particles.

The typical bright-field TEM (BF-TEM) image of a $\beta-\mathrm{Mo}_{2} \mathrm{C}$ nanocrystal shows the regular hexagonal nanoplate with a lateral size of $\sim 20 \mathrm{~nm}$ supported on carbon (Fig. 2d). The highresolution TEM (HRTEM) image shows the lattice fringes (Fig. 2e, top), where the $0.26 \mathrm{~nm}$ interplanar spacing (d) corresponds to the (300) plane of $\beta-\mathrm{Mo}_{2} \mathrm{C}$. According to the atomic-resolution image and corresponding fast Fourier 
transform (FFT) pattern (Fig. 2e, bottom), the nanoplate orientation is assigned to $\beta-\mathrm{Mo}_{2} \mathrm{C}(001)$. The high-angle annular dark-field (HAADF) scanning transmission electron microscopy (STEM) image and EDS elemental maps under STEM mode reveal the uniform spatial distribution of Mo, C, and O (Fig. 2f). Note that the $\mathrm{O}$ is attributed to the surface contamination, consistent with the XPS results (Fig. 2c). The HRTEM image and corresponding FFT pattern of $\alpha-M_{1-x}$ (Fig. $2 \mathrm{~g}$, Supplementary Fig. 11) and $\eta-\mathrm{MoC}_{1-\mathrm{x}}$ (Fig. 2h, Supplementary Fig. 12) are also obtained with the orientation of $\alpha-\mathrm{MoC}_{1-\mathrm{x}}(110)$ and $\eta-\mathrm{MoC}_{1-\mathrm{x}}(116)$ for the specific samples. Nevertheless, no preferred orientation is observed for these carbide nanocrystals according to XRD results (Fig. 2a).

Phase transformation process of molybdenum carbides revealed by ab initio calculations. To explain the voltage-dependent phase formation, we first recorded the current passing through the samples and the temperature under different FJH voltages (Supplementary Fig. 13a-c). A higher voltage leads to higher temperatures and energy inputs (Supplementary Fig. 13). The maximum temperatures at FJH voltages of $30 \mathrm{~V}, 60 \mathrm{~V}$, and $120 \mathrm{~V}$ were measured to be $839 \mathrm{~K}, 1468 \mathrm{~K}$, and $3242 \mathrm{~K}$, respectively (Supplementary Fig. 14). The formation energies of $\beta-\mathrm{Mo}_{2} \mathrm{C}$, $\alpha-\mathrm{MoC}_{1-\mathrm{x}}$, and $\eta-\mathrm{MoC}_{1-\mathrm{x}}$ varied with carbon content were calculated by first-principles density functional theory (DFT) (Fig. 3a, Supplementary Fig. 15). It is found that the $\beta-\mathrm{Mo}_{2} \mathrm{C}$ phase is the most stable phase with the lowest formation energy; hence, $\beta-\mathrm{Mo}_{2} \mathrm{C}$ forms at a relatively low voltage and temperature (Fig. 3a, Supplementary Fig. 14). In contrast, the $\alpha-\mathrm{MoC}_{1-\mathrm{x}}$ and $\eta-\mathrm{MoC}_{1-\mathrm{x}}$ are metastable phases ${ }^{31}$ and are formed and stabilized at a higher temperature according to the Mo-C phase diagram. The $\alpha-\mathrm{MoC}_{1-\mathrm{x}}$ $(x=1 / 2)$ structure has a slightly higher formation energy and the same stoichiometric composition with $\beta-\mathrm{Mo}_{2} \mathrm{C}$ (Fig. 3b). Hence, the topotactic transition from $\beta-\mathrm{Mo}_{2} \mathrm{C}$ to $\alpha-\mathrm{MoC}_{1-\mathrm{x}}$ is expected when the carbon content is slightly increased (red arrow in Fig. 3a). As more carbon is incorporated into the Mo-C system, the $\alpha-M_{1-x}$ formation energy continuously increases, and the energy curve intersects with that of $\eta-\mathrm{MoC}_{1-\mathrm{x}}$ (Fig. 3a). The $\eta-\mathrm{MoC}_{1-\mathrm{x}}$ phase becomes the relatively stable phase near $x=3 / 8$ (Fig. 3b), and continues to be the stable phase up to higher carbon contents. This result shows that the carbon vacancy dominates the energy landscape of the Mo-C system, and serves as the driving factor for the topotactic transition pathway from $\beta-\mathrm{Mo}_{2} \mathrm{C}$ to $\alpha-\mathrm{MoC}_{1-\mathrm{x}}$ and then to $\eta-\mathrm{MoC}_{1-\mathrm{x}}$ phase.
The FJH process with broadly tunable energy input permits the access of the metastable phases with higher formation energy than the thermodynamically stable phase; then, the ultrafast cooling rate of the $\mathrm{FJH}$ process $\left(>10^{4} \mathrm{~K} \mathrm{~s}^{-1}\right)$ helps to kinetically retain the metastable phases, including $a-\mathrm{MoC}_{1-\mathrm{x}}$ and $\eta-\mathrm{MoC}_{1-x}$ phases, to room temperature. As a control, at the same temperature when the metastable $\alpha-M o C_{1-x}$ phase is produced by $\mathrm{FJH}$, the synthesis using a conventional tube furnace with its slow cooling rate of $\sim 10 \mathrm{~K} \mathrm{~min}^{-1}$ only produces the thermodynamically stable $\beta-\mathrm{Mo}_{2} \mathrm{C}$ phase (Supplementary Fig. 16). This explicitly demonstrates the critical role of the ultrafast cooling rate of the $\mathrm{FJH}$ process in kinetically accessing the metastable phases.

Phase dependent HER performance of molybdenum carbides. The side-by-side electrochemical comparison of the three phases of molybdenum carbide reveals the effect of the phase control on their individual intrinsic characteristics and catalytic behaviors. To demonstrate their catalytic properties, the HER performances of the three molybdenum carbide phases were measured in $0.5 \mathrm{M}$ $\mathrm{H}_{2} \mathrm{SO}_{4}$ using a standard three-electrode configuration. Linear scan voltammogram (LSV) curves of the different electrocatalysts, as well as the $\mathrm{Pt} / \mathrm{C}$ benchmark are shown in Fig. 4a. The flash graphene (FG) obtained from FJH of carbon black was used as a control and showed negligible HER activity ${ }^{36}$. The phasedependent HER activity of molybdenum carbides was observed. The overpotential $(\eta)$ versus a reversible hydrogen electrode (RHE) at geometric current densities of $10 \mathrm{~mA} \mathrm{~cm}^{-2}$ for $\beta-\mathrm{Mo}_{2} \mathrm{C}$, $\alpha-\mathrm{MoC}_{1-\mathrm{x}}$, and $\eta-\mathrm{MoC}_{1-\mathrm{x}}$ are $-220 \mathrm{mV},-310 \mathrm{mV}$, and $-510 \mathrm{mV}$, respectively (Fig. 4a). The Tafel slopes (b) for $\beta-\mathrm{Mo}_{2} \mathrm{C}, \alpha-\mathrm{MoC}_{1-\mathrm{x}}$,

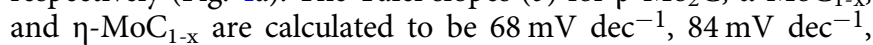
and $113 \mathrm{mV} \mathrm{dec}^{-1}$, respectively (Fig. 4b), showing the phasedependent HER reaction kinetics. The fast electrode kinetics of $\beta-\mathrm{Mo}_{2} \mathrm{C}$ phase is reflected in the small charge transfer resistance of $\sim 60 \Omega$ at the potential of $-0.5 \mathrm{~V}$ versus RHE according to the electrochemical impedance measurement (Fig. 4c). The durability of the three molybdenum carbides phases was evaluated by sweeping the electrocatalysts for 1000 cycles using the cyclic voltammetry method. The LSV curves of the 1st and 1000th cycle for the three phases of molybdenum carbides are shown in Fig. $4 \mathrm{~d}$ and Supplementary Fig. 17. No obvious current degradation was observed for all three phases, and the overpotential at $10 \mathrm{~mA} \mathrm{~cm}^{-2}$ declined little (Fig. 4d, inset), demonstrating the excellent longterm stability. a

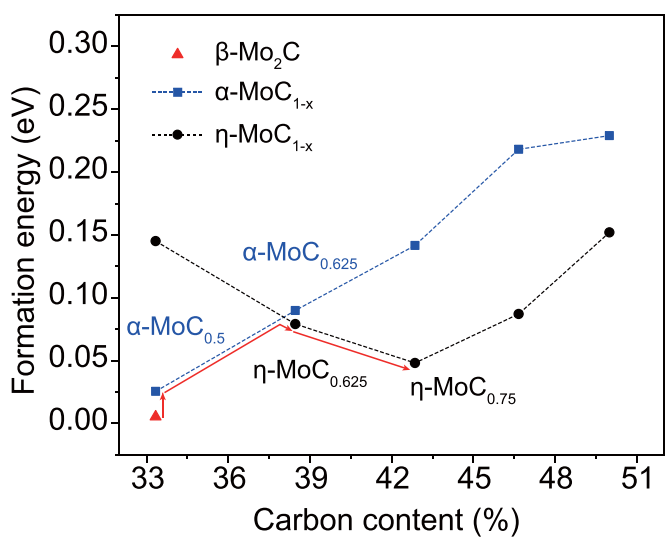

b

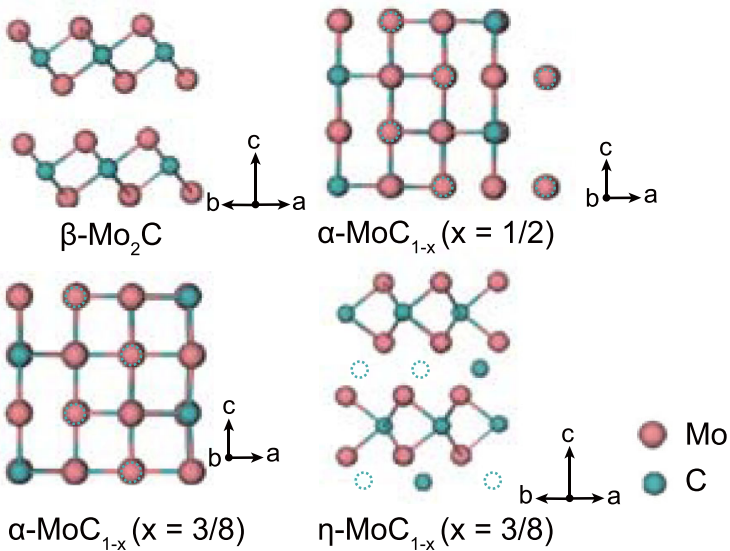

Fig. 3 Phase transformation process of molybdenum carbides revealed by density functional theory (DFT) calculations. a Formation energy of $\beta$ - $M \mathrm{o}_{2} \mathrm{C}$, and $\alpha-M_{o} C_{1-x}$ and $\eta-M_{1-x}$ with different carbon atomic content. The red line denotes the projected phase transformation pathway. $\mathbf{b}$ Calculated crystal structures of $\beta-\mathrm{Mo}_{2} \mathrm{C}, \alpha-\mathrm{MoC}_{1-x}(x=1 / 2), \alpha-\mathrm{MoC}_{1-x}(x=3 / 8)$, and $\eta-\mathrm{MoC}_{1-x}(x=3 / 8)$. The dashed circles denote the carbon vacancies. 
a

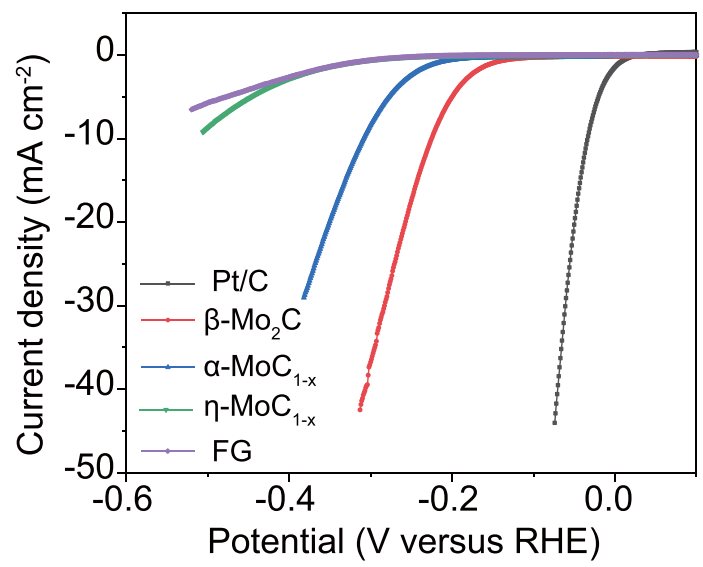

C
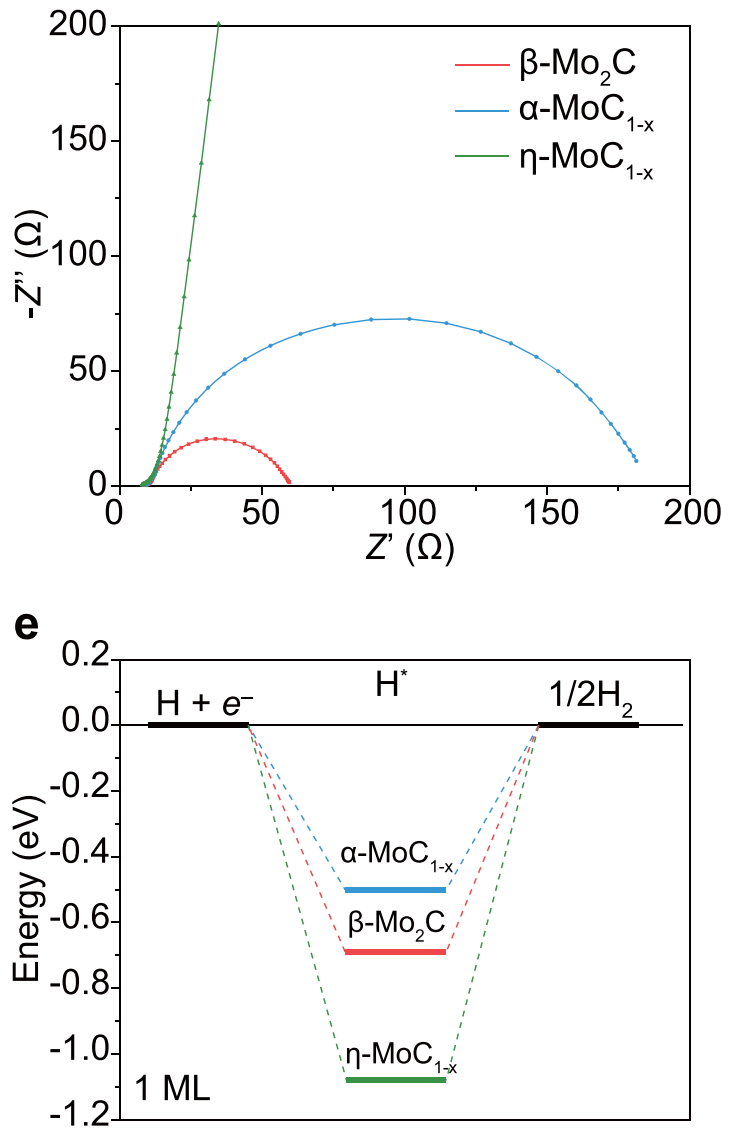

b

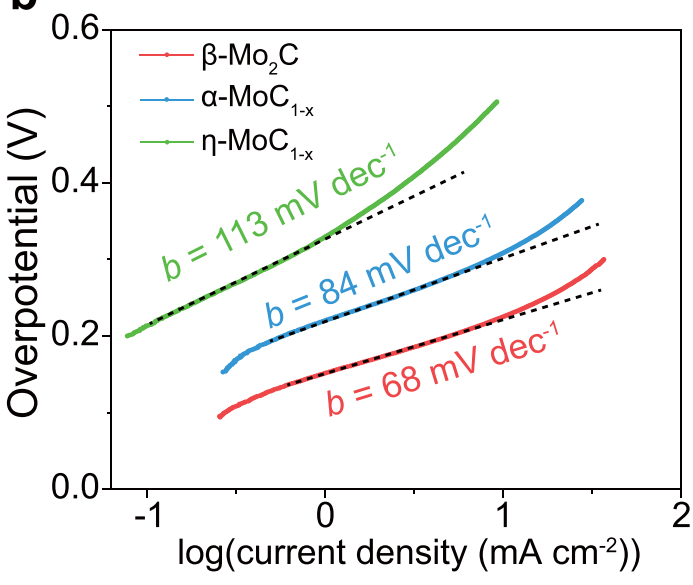

d

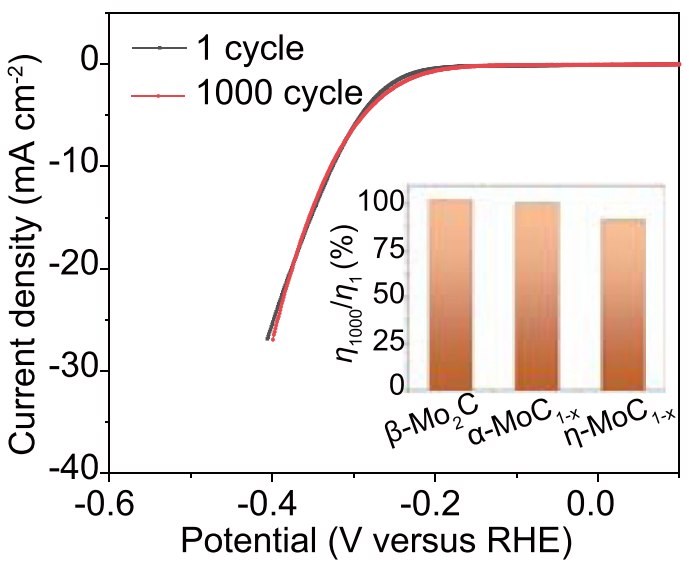

f

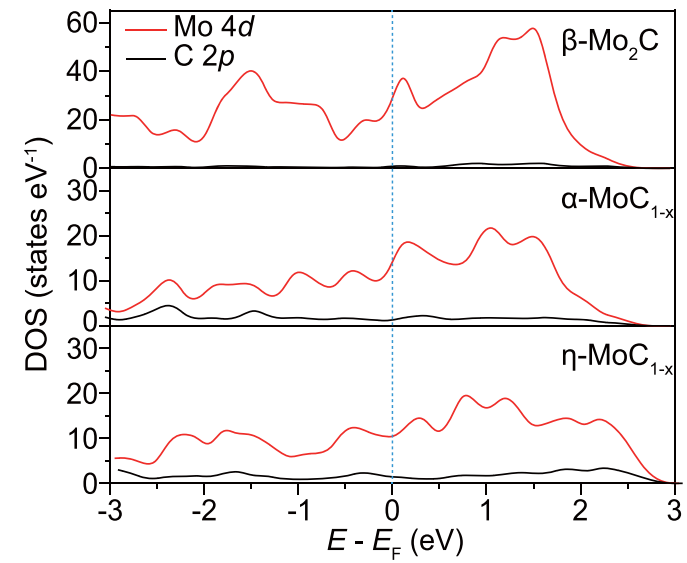

Fig. 4 Phase dependent hydrogen evolution reaction (HER) performance of molybdenum carbides. a Polarization curves of three phases of molybdenum carbide. Pt/C and pure flash graphene (FG) were used as control. The performances were normalized to the same mass loading of molybdenum carbides. b Tafel curves of three phases of molybdenum carbide. c Alternating current (AC) impedance of three phases of molybdenum carbide. $\mathbf{d}$ Durability of molybdenum carbides showing the polarization curve of $\alpha-\mathrm{MoC}_{1-x}$ for the 1st cycle and the 1000th cycle. Inset is the ratio of overpotentials at 1st cycle and 1000th cycle for three phases of molybdenum carbide. e Free-energy diagrams for $\mathrm{HER}$ on the $\beta-\mathrm{Mo}_{2} \mathrm{C}(001), \alpha-\mathrm{MoC}_{1-x}(110)$, and $\eta-\mathrm{MoC}_{1-x}(001)$ at one monolayer hydrogen adsorption coverage. $\mathbf{f}$ Calculated partial density of states of $M o$ and $C$ in $\beta-M_{2} C(001), \alpha-M o C_{1-x}(110)$, and $\eta-M o C_{1-x}(001)$. The blue dashed line denotes the position of the Fermi level.

DFT calculations were conducted to elucidate the phasedependent HER performance. The Gibbs free energy of hydrogen adsorption $\left(\Delta G_{\mathrm{H}}\right)$ has been a descriptor in the selection of HER electrocatalysts ${ }^{37}$, and optimal catalysts have $\Delta G_{\mathrm{H}}$ near $0 \mathrm{eV}$ according to the Sabatier principle ${ }^{38}$. The $\Delta G_{\mathrm{H}}$ of $\beta-\mathrm{Mo}_{2} \mathrm{C}(001)$,
$\alpha-\mathrm{MoC}_{1-\mathrm{x}}(110)$, and $\eta-\mathrm{MoC}_{1-\mathrm{x}}(001)$ were calculated to be $0.48 \mathrm{eV}$, $0.71 \mathrm{eV}$, and $1.09 \mathrm{eV}$, respectively (Fig. 4e). These results show that $\beta-\mathrm{Mo}_{2} \mathrm{C}$ and $\mathrm{a}-\mathrm{MoC}_{1-\mathrm{x}}$ have smaller hydrogen adsorption energies than $\eta-\mathrm{MoC}_{1-\mathrm{x}}$, consistent with previous reports ${ }^{33,39}$. Other than $\Delta G_{\mathrm{H}}$, the electronic structures provide valuable 
insights into the metallic character of carbide phases ${ }^{27}$. Figure $4 \mathrm{f}$ illustrates the partial density of states (DOS) of Mo and $\mathrm{C}$ in molybdenum carbides. The DOS of $\beta-\mathrm{Mo}_{2} \mathrm{C}$ near the Fermi level is substantially larger than those of $\alpha-\mathrm{MoC}_{1-\mathrm{x}}$ and $\eta-\mathrm{MoC}_{1-\mathrm{x}}$. The higher Mo content in $\beta-\mathrm{Mo}_{2} \mathrm{C}$ results in a higher carrier density and enhanced metallicity, which is beneficial for the charge transfer during electrochemical reactions (Fig. 4c). The larger surface area of $\beta-\mathrm{Mo}_{2} \mathrm{C}$ in comparison to the other two phases as measured by the Brunauer-Emmett-Teller (BET) method also contributes to the larger current density (Supplementary Fig. 18). The observed best HER performance of $\beta-\mathrm{Mo}_{2} \mathrm{C}$ is a collective effect of the relatively small hydrogen adsorption energy, enhanced metallic character, and high surface area. In addition, the flash graphene support provides a conductive pathway and prevents the carbide nanocrystals aggregating, which is beneficial for improving the HER performance $\mathrm{e}^{7,29}$.

Generalized strategy for carbide nanocrystals synthesis. Because of the ultrahigh available temperature by the FJH process, various TMCs are readily synthesized regardless of the availability of metal precursors with high vapor pressure. A series of carbide nanocrystals from transition groups IVB, VB, and VIB were successfully synthesized (Fig. 5, Supplementary Table 2). The uniform temperature distribution permits the phase-pure synthesis throughout the entire sample (Supplementary Fig. 4). According to the Ellingham diagram, the reduction temperatures of the metal oxides were calculated, which serve as reference values to evaluate carbide formation since the reaction of metal with carbon is exothermic (Fig. 5a, Supplementary Fig. 19). The ultrahigh temperature $(\sim 3000 \mathrm{~K})$ of the $\mathrm{FJH}$ process makes it possible for the reduction of all the listed oxides to elemental metals, including the most challenging $\mathrm{HfO}_{2}$ at temperature up to $\sim 2510 \mathrm{~K}$. Nearly all the low-cost metal or metal compounds, including oxides, hydroxides, and chlorides, could be used as precursors, making FJH a promising low-cost production method when compared to previous methods that rely on the availability of volatile compounds ${ }^{18,22,23}$.

Group IVB carbides only have the stable rock salt crystal structure, including $\mathrm{TiC}, \mathrm{ZrC}$, and $\mathrm{HfC}$, which are readily synthesized (Fig. 5b). The particle sizes of the $\mathrm{TiC}, \mathrm{ZrC}$, and $\mathrm{HfC}$ were measured to be $\sim 30.4 \mathrm{~nm}, \sim 38.6 \mathrm{~nm}$, and $\sim 30.6 \mathrm{~nm}$, respectively (Supplementary Fig. 20). These values matched well with the crystalline sizes determined by XRD (Supplementary Table 2), demonstrating that the as-synthesized carbide nanoparticles are mostly single-crystal. For group VB carbides, the competing $\mathrm{M}_{2} \mathrm{C}(M=\mathrm{V}, \mathrm{Nb}$, and $\mathrm{Ta})$ phases could exist at a lower $\mathrm{C}$ content ${ }^{31}$. Nevertheless, by using a large molar ratio of $\mathrm{C} / \mathrm{M}$, we successfully synthesized the pure phases of $\mathrm{VC}, \mathrm{NbC}$, and $\mathrm{TaC}$ nanocrystals with the cubic structure and particle sizes ranging from 20 to $30 \mathrm{~nm}$ (Fig. 5c, Supplementary Fig. 21). In contrast, the phases of group VIB carbide $(\mathrm{Cr}, \mathrm{Mo}$, and $\mathrm{W})$ are much more complex ${ }^{40}$. Here, the orthorhombic $\mathrm{Cr}_{3} \mathrm{C}_{2}$ phase and hexagonal $\mathrm{W}_{2} \mathrm{C}$ phase were synthesized with particle sizes of $\sim 14.2 \mathrm{~nm}$ and $\sim 18.7 \mathrm{~nm}$, respectively (Fig. 5d, Supplementary Fig. 22). $\mathrm{W}_{2} \mathrm{C}$ is not thermodynamically favored over the WC phase below $1250^{\circ} \mathrm{C}$ according to the $\mathrm{W}-\mathrm{C}$ phase diagram ${ }^{41}$. The successful synthesis of the metastable $\mathrm{W}_{2} \mathrm{C}$ is attributed to the high energy input and ultrafast cooling rate of the ultrafast electrical thermal reaction, once again demonstrating the excellent phase engineering ability of the $\mathrm{FJH}$ process. Apart from the TMCs, the covalent carbides of $\mathrm{B}_{4} \mathrm{C}$ and $\mathrm{SiC}$ were

a

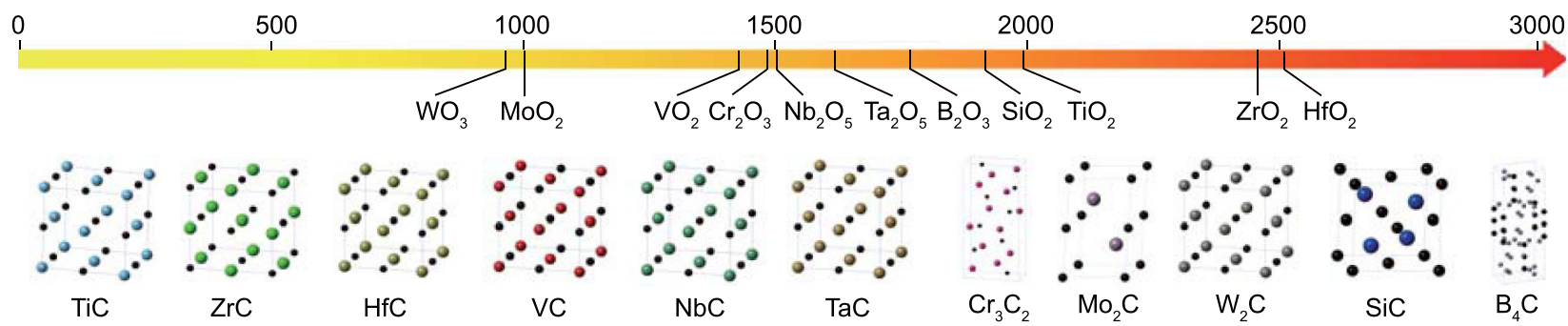

b

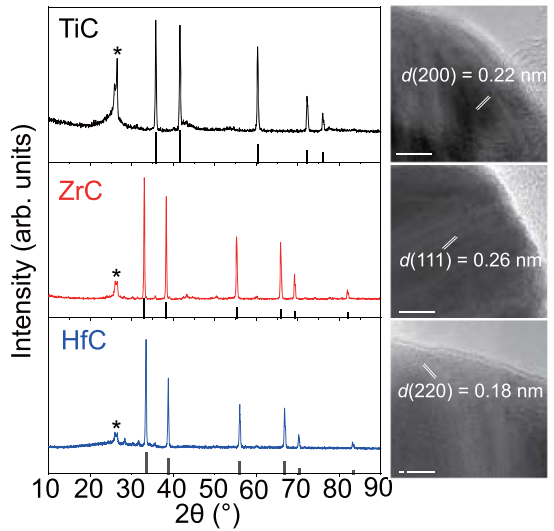

Carbothermic reduction temperature $(\mathrm{K})$

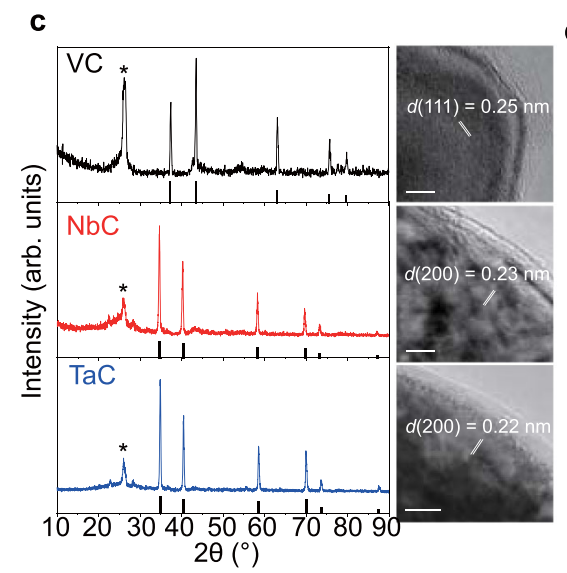

d

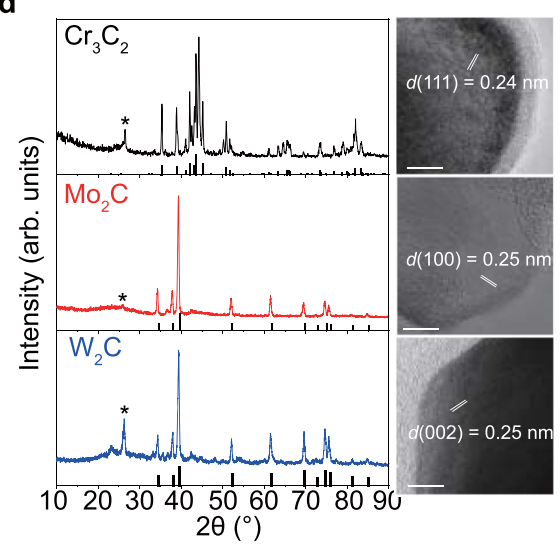

Fig. 5 Generalized strategy for carbide synthesis. a Carbothermic reduction temperature of oxides derived from the Ellingham diagram, and the crystal structures of eleven carbides. b X-ray diffraction (XRD) patterns and high-resolution transmission electron microscopy (HRTEM) images of group IVB metal carbides. The PDF reference cards for each are TiC, 65-7994; ZrC, 65-8834; and HfC, 65-7326. c XRD patterns and HRTEM images of group VB metal carbides. The PDF reference cards for each are VC, 65-8825; NbC, 65-8780; and TaC, 65-0282. d XRD patterns and HRTEM images of group

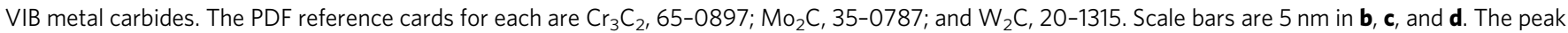
at $26^{\circ}$ (star) for all the samples is attributed to graphene support. 
synthesized (Supplementary Figs. 23, 24), further demonstrating the generality of the $\mathrm{FJH}$ process.

\section{Discussion}

The as-synthesized carbide nanocrystals are supported on flash graphene. The necessity of the separation of graphene and carbides depends on the further application. For the application of nanocrystalline carbides in electrocatalysts, the graphene support is beneficial for improving the performance by providing conduction and preventing particle aggregation (Fig. 4). For another major application of nanocrystalline carbides as precursors for ultrastrong ceramics, the removal of excess carbon is necessary. Here, we realized the efficient purification of the carbides by post-synthesis processes (Supplementary Note 2), including the simple calcination in air $^{42}$ for $\mathrm{SiC}$ (Supplementary Fig. 25); the Ca metal etching ${ }^{43}$ for TiC (Supplementary Figs. 26, 27), ZrC (Supplementary Fig. 28), HfC (Supplementary Fig. 29), VC (Supplementary Fig. 30), NbC (Supplementary Fig. 31), TaC (Supplementary Fig. 32), $\mathrm{Cr}_{3} \mathrm{C}_{2}$ (Supplementary Fig. 33), $\beta-\mathrm{Mo}_{2} \mathrm{C}$ (Supplementary Figs. 34, 35), and $\mathrm{W}_{2} \mathrm{C}$ (Supplementary Fig. 36); and the density-in-liquid purification procedure for metastable molybdenum carbides, $\alpha-\mathrm{MoC}_{1-\mathrm{x}}$ (Supplementary Fig. 37) and $\eta-\mathrm{MoC}_{1-\mathrm{x}}$ (Supplementary Fig. 38). In addition, we also demonstrated the greatly improved purity of $\mathrm{B}_{4} \mathrm{C}$ by using controlled feeding during the synthesis (Supplementary Fig. 39).

Due to the ultrafast heating/cooling rate, the direct sampling heating feature, and the short reaction duration within $1 \mathrm{~s}$, the FJH process for carbide synthesis is highly energy efficient compared to traditional furnace heating where large amounts of energy are used to maintain the temperature of the chamber. The carbide nanocrystals are synthesized at only $2.2-8.6 \mathrm{~kJ} \mathrm{~g}^{-1}$ in electrical energy (Supplementary Note 3 ). The FJH synthesis possesses excellent scalability, that a constant temperature value and uniformity on different mass scales could be obtained by adjusting the discharging voltage and/or the capacitance (Supplementary Note 4). We demonstrated the synthesis of carbide nanocrystals up to gram scale by increasing the $\mathrm{FJH}$ voltage (Supplementary Fig. 40). The FJH process is expected to be extended to the synthesis of carbide alloys ${ }^{4}$, heteroatomdecorated carbides ${ }^{34}$, and phase engineering of metastable carbides ${ }^{45}$, which provides a powerful technique for carbide production.

The controlled synthesis of metastable phases is challenging in the synthesis of inorganic materials ${ }^{46}$. The $\mathrm{FJH}$ process provides broadly tunable energy input that can exceed $3000 \mathrm{~K}$ coupled with a kinetically controlled ultrafast cooling rate $\left(>10^{4} \mathrm{~K} \mathrm{~s}^{-1}\right)$. Hence, the $\mathrm{FJH}$ process could provide access to many non-equilibrium phases and subsequently retain it at room temperature, thus serving as a potential tool for engineering the metastable phases of various materials, such as metal nanomaterials ${ }^{46}$, layered oxides ${ }^{47}$, metal nitrides ${ }^{48}$, and two-dimensional materials ${ }^{49}$.

\section{Methods}

Materials. The non-carbon precursors for carbide synthesis are $\mathrm{Ti}$ powder (Johnson Matthey, 99\%), $\mathrm{Zr}(\mathrm{OH})_{4}$ powder (Sigma-Aldrich, 97\%), $\mathrm{HfO}_{2}$ powder (Alfa Aesar, 99.95\%), $\mathrm{VO}_{2}$ powder (Alfa Aesar, $99 \%$ ), $\mathrm{NbCl}_{5}$ powder (SigmaAldrich, $99 \%$ ), $\mathrm{TaCl}_{5}$ powder (Sigma-Aldrich, 99.8\%), Cr powder (Alfa Aesar, APS $<10 \mu \mathrm{m}, 99.2 \%$ ), $\mathrm{MoCl}_{3}$ powder (Fisher Scientific, 99.5\%), $\mathrm{WO}_{3}$ powder (Johnson Matthey, 99.998\%), B powder (Alfa Aesar, 99.9\%), and $\mathrm{SiO}_{2}$ powder (Sigma-Aldrich). Carbon black (Cabot, VULCANXC72R) is used at the carbon source as well as the conductive additive.

FJH system and synthesis process. The electrical circuit diagram and setup of the FJH system are shown in Supplementary Fig. 1a, b. A capacitor bank with a total capacitance of $60 \mathrm{mF}$ was used as the power supply. The metal precursors and carbon black with specific weight ratios (Supplementary Table 2) were mixed by grinding using a mortar and pestle. The reactants $(\sim 50 \mathrm{mg})$ were loaded into a quartz tube with an inner diameter (ID) of $4 \mathrm{~mm}$ and outside diameter (OD) of
$8 \mathrm{~mm}$. When scaling up the process, a quartz tube with ID of $8 \mathrm{~mm}$ and OD of $12 \mathrm{~mm}$ was used for the $\sim 200 \mathrm{mg}$ sample, and a quartz tube with ID of $16 \mathrm{~mm}$ and OD of $20 \mathrm{~mm}$ was used for the $\sim 1 \mathrm{~g}$ sample. Graphite rods were used as the electrodes in both ends of the quartz tube. The electrodes were loosely fitting in the quartz tube to permit outgassing. The resistance was controlled by the compression force of the electrodes across the sample. The tube was then loaded on the reaction stage (Supplementary Fig. 1c). The reaction stage was loaded into a sealed reaction chamber which was evacuated to a mild vacuum $(\sim 10 \mathrm{~mm} \mathrm{Hg})$ to accommodate degassing and avoid sample oxidation (Supplementary Fig. 1d). The reaction stage was then connected to the $\mathrm{FJH}$ system. The capacitor bank was charged by a direct current (DC) supply that can reach voltages up to $400 \mathrm{~V}$. A relay with programmable ms-level delay time was used to control the discharge time. The charging, flash Joule heating, and discharging were automatically controlled by using the National Instruments Multifunction I/O (NI USB-6009) combined with a customized LabView program. After the FJH reaction, the apparatus rapidly cooled on its own to room temperature. Before removing the sample, make sure that the capacitor bank is fully discharged. The detailed conditions for the synthesis of various carbides are listed in Supplementary Table 2. CAUTION: There is a risk of electrical shock if improperly operated. The recommended safety practices were listed in the Supplementary Information.

Characterization. The SEM images and element maps by EDS were obtained using a FEI Helios NanoLab 660 DualBeam SEM system at $5 \mathrm{kV}$. The Raman spectra were acquired using a Renishaw Raman microscope (laser wavelength of $532 \mathrm{~nm}$ laser power of $5 \mathrm{~mW}$, lens of $50 \mathrm{X}$ ). XRD patterns were collected by using a Rigaku D/Max Ultima II system configured with a Cu Ka radiation $(\lambda=1.5406 \AA)$ source. The Halder-Wagner method was used for the crystal size determination. XPS analyses were conducted using a PHI Quantera XPS system under the base pressure of $5 \times 10^{-9}$ Torr. Elemental spectra were collected using a step size of $0.1 \mathrm{eV}$ with the pass energy of $26 \mathrm{eV}$. All the XPS spectra were calibrated by using the standard $\mathrm{C} 1 \mathrm{~s}$ peak at $284.8 \mathrm{eV}$. BF-TEM and HRTEM images were taken on a JEOL 2100 field emission gun transmission electron microscope under the voltage of $200 \mathrm{kV}$. STEM, HAADF, and EDS maps were obtained by using the FEI Titan Themis 3 system equipped with image and probe aberration corrections and an electron monochromator at $80 \mathrm{kV}$. BET measurements were carried out on a Quantachrome Autosorb-iQ3-MP/Kr BET Surface Analyzer, and nitrogen was used as the adsorption/desorption gas.

Temperature measurement. The temperature was measured by fitting the blackbody radiation of the sample during FJH using a homemade spectrometer (Supplementary Fig. 2). The spectral radiance from the sample was collected by a 16-channel photomultiplier tube array in the wavelength ranges of 640-1000 nm. The emission spectra were then fitted to the blackbody radiation by using the Eq. (1),

$$
B_{\lambda}(\lambda, T)=\gamma \frac{2 h c^{2}}{\lambda^{5}} \frac{1}{e^{h c / \lambda k_{B} T}-1}
$$

where $B_{\lambda}$ is the radiance, $\lambda$ is the wavelength, $T$ is the fitted temperature, $\gamma$ is a constant introduced for fitting, $h$ is the Planck constant, $c$ is the speed of light, and $k_{\mathrm{B}}$ is the Boltzmann constant. Prior to measure the sample, a $2800 \mathrm{~K}$ lamp was used to calibrate the temperature. The temperature distribution was assessed based on the optical images of the sample during FJH taken using an ultrafast camera (Chronos 1.4) and fitting of the Stefan-Boltzmann law as in Eq. (2),

$$
j^{*}=\sigma T^{4}
$$

where $j^{*}$ is the blackbody radiant emittance, $\sigma$ is a constant of proportionality, and $T$ is the thermodynamic temperature.

HER test. The binder solution was prepared by mixing of $5 \mathrm{wt} \%$ Nafion solution $(80 \mu \mathrm{L})$ with water:ethanol $(1 \mathrm{~mL}, 1: 1$, volume ratio). The catalyst ink was then prepared by dispersion of molybdenum carbides ( $1 \mathrm{mg}$, or flash graphene) into binder solution $(1 \mathrm{~mL})$ followed by ultrasonication for $1 \mathrm{~h}$. The ink $(40 \mu \mathrm{L})$ was then dropcast onto a glassy carbon electrode with a diameter of $3 \mathrm{~mm}$ (catalyst loading $\sim 0.57 \mathrm{mg} \mathrm{cm}^{-2}$ ). Electrochemical measurements were conducted using a $\mathrm{CHI} 608 \mathrm{D}$ electrochemical workstation in a $0.5 \mathrm{M} \mathrm{H}_{2} \mathrm{SO}_{4}$ solution. The standard three-electrode setup was applied, where a saturated calomel electrode (SCE) was used as the reference, the catalyst-loaded glassy carbon electrode was used as the working electrode, and a graphite rod was used as the counter electrode. Before measurement, the electrolyte was purged with Ar gas for Ar saturation. Linear sweep voltammetry (LSV) was carried out at a scan rate of $5 \mathrm{mV} \mathrm{s}^{-1}$. To compare the intrinsic properties of the three molybdenum carbide phases, the electrocatalytic performances are normalized to the same mass loading of molybdenum carbides $\left(\sim 0.074 \mathrm{mg} \mathrm{cm}^{-2}\right)$, and the trend remains the same, that $\beta-\mathrm{Mo}_{2} \mathrm{C}$ has the best performance, followed by $\alpha-\mathrm{MoC}_{1-\mathrm{x}}$, and then $\eta-\mathrm{MoC}_{1-\mathrm{x}}$ (Fig. 4). Electrochemical impedance tests were carried out in the frequency range of 100000 to $0.05 \mathrm{~Hz}$.

DFT calculation. DFT methods ${ }^{50}$ were used as they are implemented in the Vienna Ab-initio Simulation Package (VASP) ${ }^{51}$. A plane wave expansion up to $500 \mathrm{eV}$ was employed in combination with an all-electron-like projector augmented wave (PAW) potential ${ }^{52}$. Exchange-correlation was treated within the generalized 
gradient approximation (GGA) using the functional parameterized by Perdew, Burke, and Ernzerhof ${ }^{53}$. For calibration, we have calculated the three molybdenum carbides, graphite, and body-centered cubic (BCC) molybdenum metal bulk structures. Periodic boundary conditions were applied to the unit cell in all three dimensions. The Brillouin zone integrations were performed using MonkhorstPack type meshes ${ }^{54}$, with sufficient meshes of $k$-points chosen so that the energy and lattice constant were fully converged. All structures were considered to be fully relaxed when the maximum force on each atom is smaller than $0.01 \mathrm{eV} \AA^{-1}$. The calculated lattice constant of the BCC Mo metal is $3.170 \AA$. The lattice constants of graphite are $a=2.467 \AA$ and $c=7.884 \AA$. The rock-salt structure of $\alpha$-MoC has the lattice constant of $a=4.383 \AA$. The hexagonal $\beta-\mathrm{Mo}_{2} \mathrm{C}$ has lattice constants of $a=3.054 \AA$ and $c=4.816 \AA$, and hexagonal $\eta-\mathrm{MoC}$ has lattice constants of $a=3.025 \AA$ and $c=10.579 \AA$

The pristine $\alpha-\mathrm{MoC}(110), \beta-\mathrm{Mo}_{2} \mathrm{C}(001), \eta-\mathrm{MoC}(001)$ surfaces were modeled using slabs with the thickness of four bilayers $(13 \AA)$, four tri-layers $(13 \AA)$, and four quadra-layers $(20 \AA)$, respectively. Each slab has two equivalent surfaces without reconstruction except for $\eta-\operatorname{MoC}(001)$. This is because the (001) cleavage plane of the $\eta-\mathrm{MoC}$ goes between the intercalated carbon layer and $\mathrm{a}^{\mathrm{Mo}} \mathrm{C}_{2} \mathrm{C}$ trilayer. Therefore, such a cleavage results in asymmetric surfaces of one with a monolayer of $\mathrm{C}$ adatoms, and the other with no $\mathrm{C}$ adatoms. This creates a longrange dipole between the two sides of the slab, which is energetically unfavorable. To create a slab with symmetric surfaces, we divide the $\mathrm{C}$ adatoms into the two surfaces so that each surface has half a monolayer of $\mathrm{C}$ adatoms. The vacuum layer between the slabs is chosen to be $10 \AA$ or thicker. Hydrogen adsorption to the surfaces is studied by first placing a single $\mathrm{H}$ atom at all possible nonequivalent adsorption sites to determine the most favorable $\mathrm{H}$ location. Then $\mathrm{H}$ atoms are placed to all the equivalent sites. The adsorption energy per $\mathrm{H}$ atom is calculated with respect to the pristine surface and reservoir of free hydrogen molecules. We do not include the entropy here because it depends on the condition of operation.

Finally, to study the formation energy of $\alpha-\mathrm{MoC}_{1-\mathrm{x}}$ and $\eta-\mathrm{MoC}_{1-\mathrm{x}}$ phases with respect to the $\mathrm{C}$ content, we started with $2 \times 2 \times 2$ supercells of the $\mathrm{C}$-saturated $\alpha-\mathrm{MoC}$ and $\eta-\mathrm{MoC}$ crystals. Then step by step, $1 / 8$ of the $\mathrm{C}$ atoms were removed per step and the structures were relaxed. The size of the supercell was also relaxed with preserved symmetry. In each step, the removal of different $\mathrm{C}$ atoms creates different structures of vacancies. Therefore, all possible structures of $\mathrm{MoC}_{1-\mathrm{x}}$ must be calculated for a fixed $x$ to find the lowest-energy structure. For example, in $\eta-\mathrm{MoC}$ phase, removal of the intercalated $\mathrm{C}$ atoms surprisingly cost more energy than removal of the $\mathrm{C}$ atoms in the tri-layer. The formation energy is calculated using the following Eq. $(3)^{40}$,

$$
E_{\text {form }}=\frac{E\left(\mathrm{Mo}_{\mathrm{m}} \mathrm{C}_{\mathrm{n}}\right)-m E\left(\mathrm{Mo}_{\mathrm{bcc}}\right)-n E\left(\mathrm{C}_{\text {graphite }}\right)}{n+m}
$$

where $n$ and $m$ are the number $\mathrm{C}$ and $\mathrm{Mo}$ atom in the supercell of a $\mathrm{MoC}_{1-\mathrm{x}}$ structure with a total energy $E\left(\mathrm{Mo}_{\mathrm{m}} \mathrm{C}_{\mathrm{n}}\right), E\left(\mathrm{Mo}_{\mathrm{bcc}}\right)$ is the energy per Mo atom in its BCC bulk crystal, and $E\left(C_{\text {graphite }}\right)$ is the energy per $\mathrm{C}$ atom in graphite.

\section{Data availability}

The data supporting the findings of this study are available within the article and its Supplementary Information. Other relevant data are available from the corresponding author upon reasonable request. The source data generated in this study have been deposited in the Zenodo database under https://doi.org/10.5281/zenodo.5687314. Source data are provided with this paper.

Received: 18 May 2021; Accepted: 13 December 2021; Published online: 11 January 2022

\section{References}

1. Zou, J. et al. Spark plasma sintering of superhard B4CZrB2 ceramics by carbide boronizing. J. Am. Ceram. Soc. 96, 1055-1059 (2013).

2. Zhang, J. F. et al. Biomorphic cellular silicon carbide nanocrystal-based ceramics derived from wood for use as thermally stable and lightweight structural materials. ACS Appl. Nano Mater. 2, 7051-7060 (2019).

3. Reddy, K. M. et al. Enhanced mechanical properties of nanocrystalline boron carbide by nanoporosity and interface phases. Nat. Commun. 3, 1052 (2012).

4. $\quad \mathrm{Li}, \mathrm{Z}$. et al. Two-dimensional transition metal carbides as supports for tuning the chemistry of catalytic nanoparticles. Nat. Commun. 9, 5258 (2018).

5. Zhong, L. S. et al. Cobalt carbide nanoprisms for direct production of lower olefins from syngas. Nature 538, 84-87 (2016).

6. Gao, Q. S., Zhang, W. B., Shi, Z. P., Yang, L. C. \& Tang, Y. Structural design and electronic modulation of transition-metal-carbide electrocatalysts toward efficient hydrogen evolution. Adv. Mater. 31, 1802880-1802915 (2019).

7. Gong, Q. F. et al. Ultrasmall and phase-pure W2C nanoparticles for efficient electrocatalytic and photoelectrochemical hydrogen evolution. Nat. Commun. 7, 13216 (2016).

8. Han, N. N. et al. Nitrogen-doped tungsten carbide nanoarray as an efficient bifunctional electrocatalyst for water splitting in acid. Nat. Commun. 9, 924 (2018).
9. Zhang, X. et al. A stable low-temperature $\mathrm{H} 2$-production catalyst by crowding Pt on $\mathbf{a}$-MoC. Nature 589, 396-401 (2021).

10. Lin, L. L. et al. Low-temperature hydrogen production from water and methanol using Pt/a-MoC catalysts. Nature 544, 80-83 (2017).

11. Yao, S. Y. et al. Atomic-layered Au clusters on $\alpha-\mathrm{MoC}$ as catalysts for the lowtemperature water-gas shift reaction. Science 357, 389-393 (2017).

12. Rosa, C. J. Carbon diffusion in $\mathrm{Mo}_{2} \mathrm{C}$ as determined from carburization of Mo. Metall. Trans. A 14, 199-202 (1983).

13. Chen, W. F., Muckerman, J. T. \& Fujita, E. Recent developments in transition metal carbides and nitrides as hydrogen evolution electrocatalysts. Chem. Commun. 49, 8896-8909 (2013).

14. Zeng, M. \& Li, Y. G. Recent advances in heterogeneous electrocatalysts for the hydrogen evolution reaction. J. Mater. Chem. A 3, 14942-14962 (2015).

15. Oyama, S. T. Preparation and catalytic properties of transition-metal carbides and nitrides. Catal. Today 15, 179-200 (1992).

16. Wu, K. H., Jiang, Y., Jiao, S. Q., Chou, K. C. \& Zhang, G. H. Synthesis of high purity nano-sized transition-metal carbides. J. Mater. Res. Technol. 9, 11778-11790 (2020).

17. Wang, K. F., Sun, G. D., Wu, Y. D. \& Zhang, G. H. Fabrication of ultrafine and high-purity tungsten carbide powders via a carbothermic reductioncarburization process. J. Alloy Compd. 784, 362-369 (2019).

18. Kolel-Veetil, M. K., Qadri, S. B., Osofsky, M. \& Keller, T. M. Formation of a superconducting mixture of $\beta-\mathrm{Mo}_{2} \mathrm{C}$ nanoparticles and carbon nanotubes in an amorphous matrix of molybdenum compounds by the pyrolysis of a molybdenum derivative of a carboranylenesiloxane. Chem. Mater. 17, 6101-6107 (2005)

19. Wan, C., Regmi, Y. N. \& Leonard, B. M. Multiple phases of molybdenum carbide as electrocatalysts for the hydrogen evolution reaction. Angew. Chem. Int. Ed. 53, 6407-6410 (2014).

20. Claridge, J. B., York, A. P. E., Brungs, A. J. \& Green, M. L. H. Study of the temperature-programmed reaction synthesis of early transition metal carbide and nitride catalyst materials from oxide precursors. Chem. Mater. 12, 132-142 (2000).

21. Wan, J. et al. Rapid synthesis of size-tunable transition metal carbide nanodots under ambient conditions. J. Mater. Chem. A 7, 14489-14495 (2019).

22. Wolden, C. A. et al. Synthesis of $\beta-\mathrm{Mo}_{2} \mathrm{C}$ Thin Films. ACS Appl. Mater. Inter. 3, 517-521 (2011)

23. Pol, V. G., Pol, S. V. \& Gedanken, A. One-step synthesis and characterization of $\mathrm{SiC}, \mathrm{Mo}_{2} \mathrm{C}$, and WC nanostructures. Eur. J. Inorg. Chem., 709-715 (2009).

24. Wang, C. W. et al. A general method to synthesize and sinter bulk ceramics in seconds. Science 368, 521-526 (2020).

25. Giorgi, E., Grasso, S., Zapata-Solvas, E. \& Lee, W. E. Reactive carbothermal reduction of $\mathrm{ZrC}$ and $\mathrm{ZrOC}$ using Spark Plasma Sintering. Adv. Appl. Ceram. 117, S34-S47 (2018).

26. Yao, Y. G. et al. Carbothermal shock synthesis of high-entropy-alloy nanoparticles. Science 359, 1489-1494 (2018).

27. Politi, J. R. D., Vines, F., Rodriguez, J. A. \& Illas, F. Atomic and electronic structure of molybdenum carbide phases: bulk and low Miller-index surfaces. Phys. Chem. Chem. Phys. 15, 12617-12625 (2013).

28. Abrahamson, J. Graphite sublimation temperatures, carbon arcs and crystalline erosion. Carbon 12, 111-141 (1974).

29. Li, J. S. et al. Coupled molybdenum carbide and reduced graphene oxide electrocatalysts for efficient hydrogen evolution. Nat. Commun. 7, 11204 (2016).

30. Ma, R. G. et al. Ultrafine molybdenum carbide nanoparticles composited with carbon as a highly active hydrogen-evolution electrocatalyst. Angew. Chem. Int. Ed. 54, 14723-14727 (2015)

31. Hugosson, H. W. et al. Theory of phase stabilities and bonding mechanisms in stoichiometric and substoichiometric molybdenum carbide. J. Appl. Phys. 86, 3758-3767 (1999)

32. Baek, D. et al. Ordered mesoporous metastable $\alpha-\mathrm{MoC} 1-\mathrm{x}$ with enhanced water dissociation capability for boosting alkaline hydrogen evolution activity. Adv. Funct. Mater. 29, 1901217-1901225 (2019).

33. Fan, X. J. et al. Atomic $\mathrm{H}$-induced $\mathrm{Mo}_{2} \mathrm{C}$ hybrid as an active and stable bifunctional electrocatalyst. ACS Nano 11, 384-394 (2017).

34. Song, H. J., Sung, M. C., Yoon, H., Ju, B. \& Kim, D. W. Ultrafine $\alpha$-phase molybdenum carbide decorated with platinum nanoparticles for efficient hydrogen production in acidic and alkaline media. Adv. Sci. 6, 1802135-1802142 (2019).

35. Jang, H. D. \& Jeong, J. The effects of temperature on particle-size in the gasphase production of $\mathrm{TiO}_{2}$. Aerosol Sci. Tech. 23, 553-560 (1995).

36. Luong, D. X. et al. Gram-scale bottom-up flash graphene synthesis. Nature 577, 647-651 (2020).

37. Mavrikakis, M. Computational methods: A search engine for catalysts. Nat. Mater. 5, 847-848 (2006).

38. Greeley, J., Jaramillo, T. F., Bonde, J., Chorkendorff, I. B. \& Norskov, J. K. Computational high-throughput screening of electrocatalytic materials for hydrogen evolution. Nat. Mater. 5, 909-913 (2006). 
39. Matanovic, I. \& Garzon, F. H. Nitrogen electroreduction and hydrogen evolution on cubic molybdenum carbide: a density functional study. Phys. Chem. Chem. Phys. 20, 14679-14687 (2018).

40. Hugosson, H. W., Jansson, U., Johansson, B. \& Eriksson, O. Phase stability diagrams of transition metal carbides, a theoretical study. Chem. Phys. Lett. 333, 444-450 (2001).

41. Kurlov, A. S. \& Gusev, A. I. Tungsten carbides and W-C phase diagram. Inorg. Mater. 42, 121-127 (2006).

42. Pak, A. Y. et al. Silicon carbide obtaining with DC arc-discharge plasma: synthesis, product characterization and purification. Mater. Chem. Phys. 271, 124938-124944 (2021).

43. Dyjak, S., Norek, M., Polanski, M., Cudzilo, S. \& Bystrzycki, J. A simple method of synthesis and surface purification of titanium carbide powder. Int. J. Refract. Met. Hard Mater. 38, 87-91 (2013).

44. Sarker, P. et al. High-entropy high-hardness metal carbides discovered by entropy descriptors. Nat. Commun. 9, 4980 (2018)

45. Demetriou, M. D., Ghoniem, N. M. \& Lavine, A. S. Computation of metastable phases in tungsten-carbon system. J. Phase Equilib. 23, 305-309 (2002).

46. Chen, Y. et al. Phase engineering of nanomaterials. Nat. Rev. Chem. 4, 243-256 (2020).

47. Bianchini, M. et al. The interplay between thermodynamics and kinetics in the solid-state synthesis of layered oxides. Nat. Mater. 19, 1088-1095 (2020).

48. Sun, W. H. et al. Thermodynamic routes to novel metastable nitrogen-rich nitrides. Chem. Mater. 29, 6936-6946 (2017).

49. Chen, W. Y. et al. Millisecond conversion of metastable 2D materials by flash Joule heating. ACS Nano 15, 1282-1290 (2021).

50. Dudarev, S. L., Botton, G. A., Savrasov, S. Y., Humphreys, C. J. \& Sutton, A. P. Electron-energy-loss spectra and the structural stability of nickel oxide: An LSDA+U study. Phys. Rev. B 57, 1505-1509 (1998).

51. Kresse, G. \& Furthmuller, J. Efficient iterative schemes for ab initio totalenergy calculations using a plane-wave basis set. Phys. Rev. B 54, 11169-11186 (1996).

52. Blochl, P. E. Projector Augmented-wave method. Phys. Rev. B 50, 17953-17979 (1994).

53. Perdew, J. P., Burke, K. \& Ernzerhof, M. Generalized gradient approximation made simple. Phys. Rev. Lett. 77, 3865-3868 (1996).

54. Monkhorst, H. J. \& Pack, J. D. Special points for brillouin-zone integrations. Phys. Rev. B 13, 5188-5192 (1976).

\section{Acknowledgements}

We acknowledge Dr. Bo Chen from Rice University for helpful discussion of the XPS results. We acknowledge Dr. Helge Gonnermann from Rice University for allowing us to use the FEM simulation software. The funding of the research was provided by Air Force Office of Scientific Research (FA9550-19-1-0296, J.M.T.), the U.S. Army Corps of Engineers, ERDC (W912HZ-21-2-0050, B.I.Y., J.M.T., Y.Z.), and the DOE-NETL (DEFE0031794, J.M.T.). Theory-computational work was also supported by the Office of
Naval Research (N00014-18-1-2182, B.I.Y.). The authors acknowledge the use of the Electron Microscopy Center (EMC) at Rice University. The characterization equipment used in this project is from the Shared Equipment Authority (SEA) at Rice University.

\section{Author contributions}

B.D. conceived the idea of carbide synthesis by FJH. B.D. conducted the synthesis and characterizations with the help of R.A.C. The HER measurements were done by B.D., Z.W., and W.C. STEM and EDS were conducted by J.T.L. and G.G. D.X.L. designed the FJH system and temperature measurement setup. Y.Z. and B.I.Y. did the theoretical calculations. B.D. and J.M.T. wrote the manuscript. All aspects of the research were overseen by J.M.T. All authors discussed the results and commented on the manuscript.

\section{Competing interests}

Rice University owns intellectual property on the flash Joule heating strategy to prepare metal carbides. A provisional patent application has been applied for through the Rice University. The authors declare no other competing interests.

\section{Additional information}

Supplementary information The online version contains supplementary material available at https://doi.org/10.1038/s41467-021-27878-1.

Correspondence and requests for materials should be addressed to Yufeng Zhao or James M. Tour.

Peer review information Nature Communications thanks Ilya Okulov and the other, anonymous, reviewer(s) for their contribution to the peer review of this work.

Reprints and permission information is available at http://www.nature.com/reprints

Publisher's note Springer Nature remains neutral with regard to jurisdictional claims in published maps and institutional affiliations.

cc) (i) Open Access This article is licensed under a Creative Commons Attribution 4.0 International License, which permits use, sharing, adaptation, distribution and reproduction in any medium or format, as long as you give appropriate credit to the original author(s) and the source, provide a link to the Creative Commons license, and indicate if changes were made. The images or other third party material in this article are included in the article's Creative Commons license, unless indicated otherwise in a credit line to the material. If material is not included in the article's Creative Commons license and your intended use is not permitted by statutory regulation or exceeds the permitted use, you will need to obtain permission directly from the copyright holder. To view a copy of this license, visit http://creativecommons.org/ licenses/by/4.0/.

(C) The Author(s) 2022 